\title{
A Rede de Comércio Popular de Drogas Psicoativas na Cidade de Diadema e o seu Interesse para a Saúde Pública'
}

\section{The Trade Network of Psychoactive Drugs in the City of Diadema and its Interest for Public Health, São Paulo, Brazil}

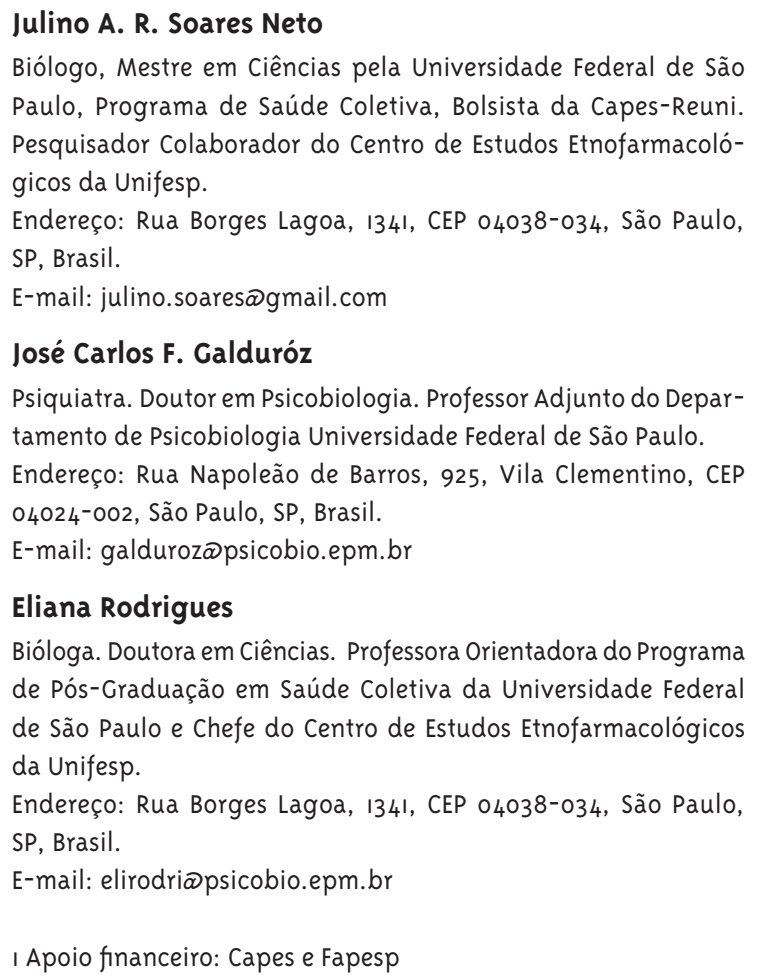

\section{Resumo}

O comércio popular de drogas vegetais sem garantia de qualidade implica risco sanitário. O presente estudo faz uma análise da rede de comércio popular de drogas vegetais psicoativas (DVPs) na cidade de Diadema e os riscos associados ao seu consumo. São apresentados dados parciais de um projeto realizado em colaboração com outras áreas de investigação. Métodos da etnofarmacologia, tais como entrevistas informais, semiestruturadas e observação participante foram utilizados para a realização do trabalho de campo, durante o qual selecionaram-se quatro comerciantes, a fim de registrar a obtenção, manipulação, acondicionamento e uso das DVPs comercializadas (nomes populares, receitas, partes utilizadas, contraindicações e doses). Foram registradas 63 DVPs distintas, e posteriormente categorizadas de acordo com suas possíveis ações psicoativas, predominando as estimulantes (67\%) e depressoras (27\%). Observaram-se deficiências na manipulação e acondicionamento das drogas por parte dos comerciantes, expondo seus clientes a possíveis riscos à saúde. Os resultados obtidos nesse estudo possibilitaram observar prioridades de adequação na comercialização de drogas vegetais no comércio popular a fim de resguardar a saúde de seus usuários, bem como a necessidade de promover um diálogo entre este e o sistema formal de saúde. Palavras-chave: Etnofarmacologia; Plantas Medicinais; Agentes Psicoativos; Medicina Popular; Saúde Pública. 


\section{Abstract}

The popular trade of herbal drugs without quality assurance implies a health risk. This study analyses the commerce network of psychoactive herbs in the streets of the city of Diadema, state of São Paulo, and the risks associated with their consumption. Data presented here are part of a project conducted in collaboration with other research areas. Several ethnopharmacological methods, including participant observation, informal and semi-structured interviews, were used to develop field work among dealers. Vernacular names of the commercialized herbs, their formulae, utilized parts, contraindications, doses, origin were recorded, and also how they were obtained, manipulated, stocked, packaged and used. The study registered 63, herbs, which were categorized according to their possible psychoactive actions. The stimulants (67\%) and the depressants (27\%) predominated. Shortcomings were observed in the stock, manipulation and packaging of the drugs, exposing their customers to health risks. These findings aid in the understanding of aspects related to the quality and safety of herbs that are informally traded in Diadema, and show the need to promote a dialogue between this system and the formal health system.

Keywords: Ethnopharmacology; Medicinal Plants; Psychoactive Agents; Popular Medicine; Public Health.

\section{Introdução}

Estima-se que mundialmente 450 milhões de pessoas sofrem de alguma doença mental ou distúrbios de comportamento. Apesar dos esforços, a saúde mental ainda não é vista com a mesma prioridade e importância que a saúde física. A definição de saúde mental pela World Health Organization (WHO) é:

[...] a state of complete physical, mental and social well-being and not merely the absence of disease or infirmity (2003, p. 7).

O uso de plantas medicinais no alívio das desordens mentais é anterior ao advento das modernas drogas farmacêuticas (Spinella, 2002); tem seu significado e importância baseados nas práticas populares, e jamais foram substituídas completamente por fármacos sintéticos (Niero e col., 2003).

Diversos campos da ciência têm-se dedicado à pesquisa das plantas medicinais, sendo a etnofarmacologia uma importante disciplina na investigação das formas de uso dos recursos naturais pelas populações humanas. A etnofarmacologia como campo especificamente de pesquisa tem uma história relativamente curta (Heinrich e col., 2004). Bruhn e Holmstedt (1981) definem esse campo como:

Ethnopharmacology is here defined as 'the interdisciplinary scientific exploration of biologically active agents traditionally employed or observed by man'.

Entende-se por droga vegetal (DV) a planta medicinal ou suas partes, após processo de coleta, estabilização e secagem, podendo ser íntegra, rasurada, triturada ou pulverizada (Brasil, 2004). Segundo Delay e colaboradores (1959), as drogas psicoativas são aquelas que agem modificando aspectos fisiológicos e comportamentais do ser humano, como a capacidade cognitiva, os padrões de pensamento e o humor. De acordo com as modificações fisiológicas que provocam, podem ser classificadas como: estimulantes, depressoras ou alucinógenas.

Embora o uso medicinal de plantas/drogas vegetais (DVs) faça parte da história da humanidade, poucos pesquisadores têm-se dedicado a entender as complicações e riscos que podem advir do uso desse tipo de "medicamento" (Farias e col., 1985; Barnes e col., 1998; Elvin-Lewis, 2001; Caldas e 
Machado, 2004; Veiga Junior e Pinto, 2005; Turola e Nascimento, 2006). E, em menor quantidade ainda, são os que buscam descrever não apenas os aspectos terapêuticos, mas também o "lado ruim" das plantas/ drogas, segundo a percepção das próprias culturas (Rodrigues, 2007).

Em áreas urbanas, é comum encontrar DVs comercializadas em barracas de rua sem controle de qualidade, fiscalização sanitária e comprovação científica, oferecendo riscos aos seus consumidores. Pela complexidade das exigências do comércio formal de DVs, a investigação da rede de comércio popular de DVs em Diadema necessita ser abordada e de modo interdisciplinar, contribuindo para a Saúde Pública. $\mathrm{O}$ objetivo do presente trabalho foi realizar um levantamento etnofarmacológico entre os comerciantes de drogas vegetais psicoativas (DVPs) na cidade de Diadema. Tal levantamento possibilitou o entendimento desta rede de comércio, bem como a verificação do acondicionamento e da manipulação das DVPs pelos comerciantes e possíveis riscos envolvidos; e possibilitou compreender, ainda, as indicações de uso e formas de preparo das drogas.

São apresentados dados parciais de um projeto realizado em colaboração com outras áreas de investigação, respectivamente: microbiologia, farmacognosia e farmacovigilância. Tendo como objetivo analisar, do ponto de vista interdisciplinar, a cadeia de comércio das DVPs na cidade de Diadema e seus possíveis impactos na saúde dos consumidores.

\section{Métodos}

\section{Área de estudo}

O trabalho de campo foi realizado no município de Diadema, localizado a 17 quilômetros da cidade de São Paulo. Diadema pertence à região do Grande ABCD e possui um Índice de Desenvolvimento $\mathrm{Hu}$ mano (IDH) de o,79 (IPEA, 200o).

\section{Seleção dos entrevistados}

Após levantamento preliminar dos comerciantes de DVs em todos os bairros do município de Diadema, estes foram selecionados durante entrevistas informais mediante três critérios, nesta ordem de importância: A) Comercializar DVs com indicação de uso, com possível atividade psicoativa, ou seja, calman- tes, afrodisíacos, tônicos, entre outras; B) Tempo de trabalho: os mais antigos devem concentrar grande experiência no comércio das DVs, portanto possuir grande número de clientes; C) Idade: Acredita-se que os comerciantes mais velhos possuam conhecimento "superior" em relação aos mais jovens, muito embora nem sempre isso seja uma realidade.

\section{Levantamento etnofarmacológico}

Para o desenvolvimento do trabalho de campo utilizaram-se os seguintes métodos e técnicas da etnografia: observação participante, entrevistas informais e semiestruturadas bem como anotações em diário de campo (Bernard, 1988; Malinowski, 1990; Foote-Whyte, 1990; Martin, 1995; Alexiades, 1996).

As entrevistas semiestruturadas foram guiadas por duas fichas: uma de Dados Etnofarmacológicos contendo informações acerca das indicações de uso das DVPs, formas de preparo, via de administração, doses e contraindicações. A segunda, Ficha de Dados do Comerciante, que, além de traçar seu perfil socioeconômico, fornece dados sobre a procedência das DVPs, detalhes da sua estocagem e manipulação.

\section{Categorização das DVPs}

A correlação entre as indicações terapêuticas citadas pelos comerciantes - utilizando-se de termos médicos e populares - e as doenças e os quadros clínicos da medicina oficial foi feita por uma equipe composta por psiquiatra, farmacêutico e biólogos. Da mesma forma, os termos médicos referentes a cada droga foram categorizados em estimulantes, depressoras ou alucinógenas.

\section{Resultados}

\section{Perfil dos comerciantes}

Foram identificados 11 comerciantes que vendem DVs informalmente na cidade de Diadema, sendo que, destes, quatro foram selecionados para participar do projeto de acordo com os critérios previamente estabelecidos. Todos são homens e originários da região nordeste do País, sendo identificados como "OV" (49 anos), "LA" (6o anos), "BE” (62 anos) e "OT" (9o anos). Além disso, relataram que iniciaram em seus locais de origem, dentro do grupo familiar e da comunidade, seu aprendizado sobre o uso das plan- 
tas medicinais, recorrentes em suas localidades.

O tempo de trabalho (comércio de DVs) apresentou grande variação, entre seis e 54 anos. Aparentemente a média de clientes não foi proporcional ao tempo de trabalho/experiência do comerciante, ficando entre 10 e 50 clientes/dia, segundo os entrevistados. A renda bruta declarada ficou entre R\$ 300,00 e 5.500,00, e a renda líquida entre R\$ 116,00 e 4.250,oo. Todos possuíam baixa escolaridade, não tendo concluído o ensino fundamental.

\section{O Perfil das drogas}

As DVs podem ser compostas por uma única planta ou várias (chá 7 ervas, chá 11 ervas, chá 18 ervas, composto emagrecedor 30 ervas e composto emagrecedor 37 ervas), sendo estas as mais vendidas. É assumida a ideia do poder cumulativo das plantas onde a sua combinação fará com que seus efeitos sejam potencializados. As populares garrafadas (mistura de 10 ou mais ervas em solução alcoólica, geralmente de vinho tinto) são produtos indispensáveis na medicina popular e são muito indicadas nos tratamentos; seu preço variou de $\mathrm{R} \$$ 40,0o a R\$ 75,oo. Já o valor médio das DVPs ficou em R\$ 4, oo a unidade (o saquinho).

O presente estudo ocupou-se apenas das DVPs compostas por uma única planta, visto que este estudo faz parte de um maior, conforme citado anteriormente, que visa avaliar a qualidade das drogas (para o qual vem utilizando métodos da microbiologia e farmacognosia) e riscos envolvidos no seu uso (métodos da farmacovigilância). Portanto, num primeiro momento, não seria factível realizar uma análise a partir de "polidrogas", dada a complexidade das variantes envolvidas.

Durante as entrevistas foram catalogadas $63 \mathrm{DVs}$ que remetiam à atividade psicoativa (DVPs), segundo a indicação de uso, e foram categorizadas em: estimulantes (67\%), depressoras (27\%), depressoras e estimulantes (1\%) e finalmente algumas não puderam ser definidas ( $5 \%$ ). Assim, os termos citados pelos comerciantes: "para acalmar", "combater a insônia", "sedativo", "epilepsia”, "histeria”, "angústia”, "relaxante" e "ansiedade" foram categorizadas como depressoras, enquanto os usos "para combater a fraqueza", "estimulante", "tônico", "emagrecimento", "impotência”, "aperiente", "afrodisíaco” e "memória” foram categorizados como estimulantes. Não houve relato de drogas para a categoria alucinógena. As DVPs que estavam presentes em ambas as categorias estimulantes e depressoras são aquelas que receberam indicações ao mesmo tempo de "calmante" e "estimulante" (como no caso da cúrcuma); "antidepressivo" e "calmante" (hipérico), e ainda "insônia" e "tônica" (camomila).

Observou-se o predomínio de indicações de uso pertencentes à categoria estimulantes, entre os quais tiveram maior frequência o estimulante (20\%), para combater a fraqueza (19\%) e tônica (18\%) (Figura 1).

Figura I - Frequência relativa (\%) dos usos pertencentes à categoria estimulantes

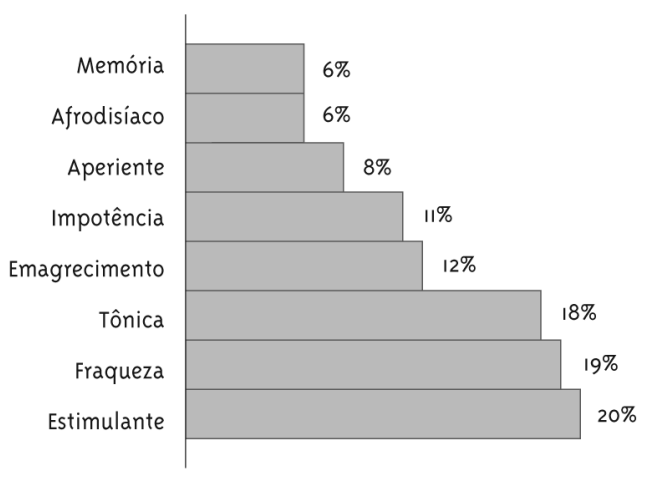

Entre os usos que remetem à categoria depressora predominaram os "calmantes" (35\%) e para combater "problemas de insônia" (29\%) (Figura 2).

\section{Figura 2 - Frequência relativa (\%) dos usos pertencentes} à categoria depressoras

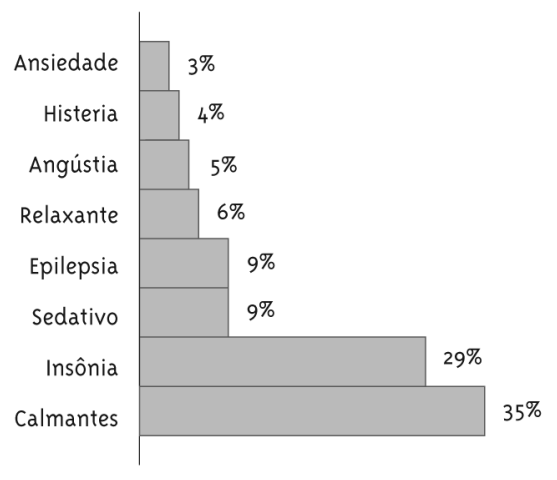


Embora tenham sido novamente verificados entre os entrevistados, alguns termos médicos de uso popular permaneceram sem categorização, uma vez que apresentaram sentido dúbio/vago. As DVPs pertencentes a estes usos perfazem um total de $5 \%$, entre eles: "bom para a mente", "para o sexo", "neuroses", "bom para os nervos", "para o sistema nervoso central”.

As formas de preparo mais frequentes foram: decocção (43\%) e infusão (25\%), sendo as folhas e flores (partes moles) "abafadas" (infusão) e as partes duras, tais como cascas, sementes e raízes em geral devem ser "cozidas" (decocção). Todas as DVPs em pó tiveram a indicação para serem solubilizadas em água, leite ou suco, e em alguns casos foi recomendado colocar na comida. A via de administração indicada foi exclusivamente a oral.

A indicação da dose e a administração do chá (quantas vezes ao dia) variaram principalmente segundo os critérios de idade do cliente e a gravidade da doença. Pode-se utilizar de duas a três colheres de chá ou sopa para um copo americano tomado de duas a três vezes ao dia ou também se pode optar por fazer um litro do chá e conservar na geladeira. A indicação do uso de chás para crianças e gestantes apresentou forte resistência. Para as crianças pequenas indica-se metade da dose; já as crianças de colo não podem ingeri-los, com exceção da camomila e erva-doce para cólicas. As gestantes receberam as mesmas restrições,metade da dose, mas sendo necessária uma conversa mais detalhada com o comerciante para liberar o seu consumo, segundo critérios individuais de seleção das DVPs e avaliação do caso. Apesar de terem demonstrado preocupações e restrições na indicação das DVPs para gestantes, um dos entrevistados foi mais flexível, recomendando o consumo de várias drogas.

A indicação das DVPs é feita de diferentes formas, mas o comum é que o cliente já tenha o diagnóstico da doença fornecida por um médico ou por automedicação. A partir disso, podem-se recorrer aos livros ou às demais fontes de informação, inclusive para reforçar seu conhecimento ou experiência no uso das DVPs.

Dentre as 63 DVPs, foram selecionadas 18 (catuaba, cipó-cravo, guaraná, maracujá, marapuama, melissa, mulungu, nó-de-cachorro, olho-de-boi, tília, anis-estrelado, camomila, erva-de-são-João, ginkco biloba, ginseng, jatobá, tríbulos e valeriana), somando um total de 70 amostras adquiridas dos quatro comerciantes. No momento, estão sendo alvo de análises laboratoriais (microbiológica e farmacognóstica) e será objeto de futura publicação.

\section{Perfil de comércio}

Todos os comerciantes compram as DVs exclusivamente em atacadistas da região central de São Paulo, e relataram usar sua experiência para identificar o produto que estão comprando principalmente através da cor, do odor e do formato.

A reposição do estoque é feita, em média, a cada 15 dias. As DVs são compradas em grande quantidade e fracionadas para venda no próprio local de comércio ou em casa, sem o uso de equipamentos de proteção. O próprio local onde as drogas são armazenadas e manipuladas podem apresentar riscos de contaminação, pois são locais abertos e próximos de vias com forte tráfego de automóveis; alguns sacos plásticos contendo as DVs apresentavam uma película de fuligem em sua superfície. Dois dos entrevistados, após o fracionamento, utilizam rótulo personalizado nas embalagens, enquanto outros simplesmente mantêm os sacos originais abertos na barraca, e vendem as drogas por colheradas ou porções ("uma mão"), embaladas posteriormente em um saco de papel. Observou-se que a rotulagem não obedecia aos critérios exigidos pela legislação (Brasil, 2010).

A estocagem das DVs apresentou-se como um dos pontos mais críticos, pois os comerciantes praticamente não possuem um sistema de operacionalização do estoque tendo em vista a preservação da qualidade, validade e mistura dos lotes. Todos os comerciantes se mostraram preocupados com a qualidade e com a validade do produto comercializado, no entanto, foi possível observar a mistura de diferentes lotes de algumas DVs.

Segundo um dos comerciantes, as sementes e grãos precisam ser colocados em vidros, pois os ratos podem furar os sacos contendo essas drogas. Em geral as barracas não possuíam local adequado de estocagem, ficando as DVs amontoadas na barraca ou no chão, mas alguns comerciantes já estão fazendo modificações na organização do estoque, melho- 
rando a forma de embalagem e acondicionamento das drogas estocadas, e até mesmo informatizando o controle de vendas.

Um dos comerciantes selecionado neste estudo acondicionava as DVs em um estacionamento/oficina muito sujo e em área aberta, ficando a barraca exposta ao tempo.

\section{Discussão}

Podemos considerar que os comerciantes selecionados conseguiram estruturar uma importante rede de comércio de DVs, coexistindo com outros estabelecimentos de saúde, drogarias e com a própria biomedicina. Além disso, diferentemente dos demais comerciantes identificados, gozam de maior credibilidade e prestígio exercendo grande influência nas práticas locais de medicina popular e no fornecimento de DVs. São reconhecidos pela população, e até por algumas importantes autoridades públicas, como referência no uso de "plantas medicinais".

Devido à grande variedade de DVs encontradas nos comércios atacadistas, e ao perfil variado de clientes e doenças/queixas, os comerciantes devem se adequar a esta realidade. Para tanto, lançam mão de diferentes fontes de informação e cursos com especialistas. Também incorporam símbolos (jaleco branco) e termos da medicina oficial; não é raro ouvir um discurso conciliador com a medicina oficial: "tem que ter ciência e experiência” (OT).

Entretanto, todos os entrevistados apresentaram muitas críticas ao modelo biomédico, dizendo não confiar no julgamento e avaliação do médico e na eficácia dos medicamentos alopáticos, tendo nas "plantas medicinais" uma forma de resistência ao modelo imposto. Apesar disso, já é possível observar o uso de nomes de medicamentos para identificar as plantas de uso medicinal, tal como aspirina, anador, buscopan entre outros (Pires e col., 2009), e isso é feito não apenas por seu efeito terapêutico atribuído em comparação ao alopático, mas como forma de legitimar seu uso frente à medicina oficial.

Um aspecto importante identificado nesta pesquisa foi a fonte secundária de informação, tais como livros, revistas, folhetos e televisão. Estas são ferramentas essenciais de trabalho para a pesquisa da grande diversidade de plantas, quer seja para adquirir novos conhecimentos, ou mesmo para confirmar as indicações de uso. A dinâmica das informações dá-se por um fluxo não linear e não se baseia necessariamente na experiência de uso do comerciante ou mesmo no contato pessoal. Desta forma, o conhecimento sobre o uso das plantas pode vir de amigos, vizinhos, do balcão da farmácia, do consultório médico ou dos próprios clientes. É importante destacar que os livros foram apresentados como um elemento fundamental na indicação das DVPs e na incorporação de novos "termos médicos”. Além das informações adicionais, os livros transmitem segurança para os usuários e para os próprios comerciantes; conforme citado por um dos comerciantes não apresentado neste estudo: "se o cliente vier reclamar, ou acontecer algum problema, a responsabilidade é de quem escreveu o livro".

Além das terminologias incorporadas para descrever as queixas dos clientes, também fica evidente a dificuldade que o comerciante tem de compreender o quadro desses transtornos mentais, diante da sua complexidade e diversidade, encontrados nos grandes centros urbanos. É comum ouvir o discurso de que a depressão é um problema espiritual ou que sua causa é um desvio da conduta da vida social ("preguiça").

Segundo relatado, muitos clientes também já sabem quais DVPs devem usar para a queixa apresentada (automedicação), sendo que muitas vão ao encontro das indicações apontadas pelos comerciantes. Desta forma, o conhecimento de uso das DVPs também se dá na relação com o cliente, o que dificulta a compreensão da fonte inicial da informação.

Além disso, deve-se considerar a disponibilidade crescente do acesso às informações sobre o uso de plantas medicinais por meio de internet e televisão. Neste cenário destaca-se o impacto que a mídia tem sobre a credibilidade no uso das plantas medicinais e sua influência no consumo:

Quando a Ana Maria Braga fala que uma planta éboa pra isso ou pra aquilo, no dia seguinte todo mundo quer comprar (OT).

A medicina popular diversificou-se nos centros urbanos como resultado do processo migratório de diversas culturas ao longo do território, recebendo diversas influências. 
A medicina popular sofre, como todo fenômeno cultural e social, a influência indireta dos meios intelectualizados e da comunicação. Essa influência é justificada pelas modificações que vão sofrendo, com o tempo, os conceitos, usos e costumes. Assim, processa-se o fenômeno da aculturação, corroborada também pelo relacionamento entre os elementos de diversas regiões do país, que habitam as mesmas áreas, o que vem facilitar a transmissão e, consequentemente, a assimilação recíproca dos traços culturais. Portanto, os mecanismos de defesa contra as doenças, no campo da medicina popular, não são apenas formas de comportamento herdadas: são aprendidos e modificados lentamente dentro dos grupos sociais (Camargo, 1998, p. 187).

Existe ainda a preocupação em tentar estruturar seus pontos de comércio de modo a assemelharemse aos estabelecimentos pertencentes ao sistema oficial de saúde, modernizando-os periodicamente. Pois aparentemente o número de clientes atendidos também se relaciona à estrutura física do ponto de comércio; uma barraca de rua, com plantas em sacos vendidas a granel, transmite pouca credibilidade quando comparada à estrutura de uma loja com as DVs expostas em prateleiras de vidro e uma grande diversidade de produtos (inclusive DVs em cápsulas). Investem em publicidade através de folhetos e pintura de muros, divulgando seus produtos e serviço, chegando até a estruturar um "sistema delivery". Utilizam frases persuasivas a fim de se destacarem no mercado e ressaltarem suas qualidades:

Você não aguenta mais tomar tanto remédio? Dê um basta neste sofrimento que te atormenta dia e noite. Seja qual for a sua doença, faça uma consulta com o 'OV' e veja o resultado.

Segundo os entrevistados, a clientela é majoritariamente de mulheres, mas quando separadas por categoria de uso, as mulheres consumiram preferencialmente as DVPs com indicações depressoras (calmantes, insônia, ansiedade) e estimulantes (emagrecedor), enquanto os homens apresentam consumo restrito às estimulantes (afrodisíacos, tônicos, fortificantes). Quanto à idade, essa variável não apresentou diferenças relevantes.

É importante notar que existe uma grande clientela masculina em busca de afrodisíacos e energéticos oriunda das academias de ginástica (usam preferencialmente o ginseng e nó-de-cachorro) e principalmente das indústrias, amplamente distribuídas nesta cidade. Além dos relatos, observou-se que esses trabalhadores consomem as DVPs (guaraná, catuaba entre outras) nas próprias barracas, de três a quatro doses além do recomendado, pois "dá mais força para trabalhar”, e mais uma ou duas doses em casa ao retornar do trabalho, como afrodisíaco.

O abuso de substâncias para aumentar o desempenho físico tem causado graves problemas à saúde. A banalização do uso dos anabolizantes, suplementos e energéticos utilizados para o rápido ganho de massa muscular ou o uso indevido de medicamentos para disfunção erétil (inibidores da fosfodiesterase-5) é cada vez mais comum entre jovens e universitários (Ribeiro, 2001; Freitas e col., 2008). As drogas estimulantes também são utilizadas por motoristas profissionais de caminhão que têm longas jornadas de trabalho, sendo as anfetaminas consideradas um fator de risco em acidentes de trânsito (Pinho, 2005).

Um amplo levantamento domiciliar sobre o uso de drogas psicotrópicas no Brasil (Carlini e Galduróz, 2006) demonstra que 3,2\% da população já fez uso de algum estimulante, o que representa um universo de 1.605.0oo pessoas, sendo nítido o predomínio das mulheres sobre os homens $(4,5: 1,1)$ em relação aos anorexígenos. Os benzodiazepínicos foram usados por $5,65 \%$ da amostra (2.841.0oo pessoas) e mais uma vez as mulheres ficaram na frente: $6,9 \%$ para as mulheres contra $3,4 \%$ dos homens. Isto se deve provavelmente a um comportamento aprendido com as mães. Os homens bebem para se tranquilizar.

O uso de termos médicos na medicina popular, como "epilepsia", exemplifica a dificuldade que o pesquisador da área de etnofarmacologia encontra ao tentar estabelecer uma correlação entre um termo da etnomedicina e aquele da medicina oficial. Algumas vezes, tal correlação fica totalmente prejudicada pela dificuldade de "tradução" daqueles termos populares. Tal "tradução" poderia ser comparada a um tipo de "quebra-cabeça etnofarmacológico" e trata-se de um dos maiores desafios do pesquisador que realiza levantamentos etnofarmacológicos, sobretudo pela ausência de profissionais da área médica acompanhando os trabalhos de campo que 
muito poderiam contribuir para estabelecer aquela correlação (Rodrigues, 2007). Desta forma, optouse por manter, neste estudo, os termos locais, da forma como foram citados pelos comerciantes. No contexto urbano essa dificuldade se amplia, na medida em que existem influências das diversas mídias, de diferentes grupos culturais e da própria medicina oficial.

A distorção que pode haver no uso das terminologias e informações médicas representa um risco potencial, pois modifica o conhecimento das práticas tradicionais e pode interferir na adesão ou condução do tratamento prescrito pelo médico. A difusão dessas informações para o público leigo necessita ser avaliada segundo o interesse da promoção da saúde, e considerando a cultura popular como um elemento de interlocução.

Também não podemos perder de vista que as plantas medicinais são utilizadas dentro de um contexto cultural e histórico. Portanto, possuem suas representações simbólicas e um sistema teórico de explicação do processo de saúde/doença e na caracterização das enfermidades e dos doentes (Araújo, 2002).

Entretanto, apesar da grande aceitação popular, do baixo custo e da "modernização" da medicina popular, muitos estudos têm apontado que o uso de DVs não garante a total segurança e eficácia frequentemente acreditada. Dentre os riscos, podem ocorrer interações entre eles ou com medicamentos alopáticos e alimentos, produzindo efeitos tóxicos ou não desejados (Calixto, 20oo; Moura e Reyes, 2002; Spinella, 2002). Desta forma, o uso por gestantes, idosos, crianças e pessoas imunodeprimidas deve ser considerado como um risco adicional e reforçado em campanhas de uso racional desse tipo de medicamento, tanto para profissionais da saúde como para a população (Tiran, 2003; Niggemann e Grüber, 2003; Nordeng e Havnen, 2005).

Os comerciantes entrevistados adquirem e vendem as DVPs segundo os nomes populares pelos quais as respectivas plantas são conhecidas, embora se saiba que possa ocorrer mais de um nome popular para a mesma planta. Neste sentido, torna-se necessário que ele use sua experiência para identificar as DVPs pelas suas características organolépticas (principalmente através da cor, do odor e do for- mato). No entanto, sabe-se que esta identificação é limitada, demonstrando a dificuldade e o risco que existem em comercializar DVs pelos nomes populares. Também observou-se que os comerciantes não possuem conhecimentos para saber a respeito dos nomes científicos das plantas (DVs) adquiridas do fornecedor/atacadista, por desconhecerem esta necessidade. Isso é importante, pois segundo relatado, algumas destas, comercializadas pelos atacadistas, não correspondiam às plantas reconhecidas pelos entrevistados; inequivocamente a comercialização de DVs em pó facilitaria ainda mais a sua adulteração.

A observação das formas de manipulação das DVs evidencia que tais condutas favorecem a contaminação e proliferação microbiológica e a perda da qualidade da matéria-prima, o que não deixa de ser uma preocupação conforme citado pelos próprios entrevistados.

O processo de acondicionamento e fracionamento, além de determinar as quantidades do produto a serem fornecidas ao cliente, quando feito de forma inadequada pode apresentar diversos tipos de contaminação e a consequente perda da sua qualidade, além das questões de validade e quantidade da DVP que será consumida. Por exemplo, a umidificação das embalagens (quando mal seladas ou acondicionadas em locais úmidos) favorece o desenvolvimento de fungos, diminuindo a validade do produto e possibilitando a contaminação por micotoxinas.

Segundo informado pela vigilância sanitária do município, para comercializar as DVs é necessária uma autorização específica da prefeitura, mas muitos comerciantes de temperos acabam incorporando as DVs aos demais produtos. No Brasil as ações de fiscalização do comércio informal de DVs ainda são ineficientes. Todavia, também devemos considerar a complexidade da questão, como a estrutura para fiscalização, o acesso da população carente aos medicamentos, a influência cultural e da mídia, e as políticas públicas de regulamentação do setor.

Compreender a rede de comércio de DVPs na cidade de Diadema observando o processo de estocagem, conservação, higiene na manipulação, e tempo de descarte, mostrou importantes implicações para a saúde pública. Essas informações contribuem para a construção de propostas de adequação dessa atividade e no desenvolvimento de ações para promover 
o uso racional de DVPs. Além disso, é urgente a necessidade de se pensar o lugar do comércio popular de DVs em grandes centros urbanos atualmente.

Por ser esse um campo de conflitos, considerando as disputas comerciais e os órgãos sanitários ou a busca da legitimidade ora frente à medicina popular, ora frente à medicina oficial, foi fundamental a abordagem da etnofarmacologia para adentrarmos nesse ambiente e realizarmos uma análise.

É preciso dialogar e negociar com esses comerciantes sobre a importância de algumas transformações em suas práticas. 0 desejo de ter acesso a livros e uma formação, por parte dos comerciantes, baseada nas informações científicas indicam um possível caminho para que os órgãos de saúde iniciem de forma simples seu processo de adequação e se estabeleça um diálogo. A Organização Mundial da Saúde (1978) reconhece a importância da medicina popular e recomenda de forma estratégica que esta seja vista como aliada na promoção da saúde. Entretanto, o Brasil ainda não tem uma proposta definida quanto a isso.

\section{Agradecimentos}

Ao Prof. Dr. Luis Carlo Marques, da Universidade Bandeirantes, pelos comentários durante o trabalho de campo.

\section{Referências}

\section{ALEXIADES, M. N. Selected guidelines for} ethnobotanical research: a field manual. New York: The New York Botanical Garden, 1996.

ARAÚJO, M. Das ervas medicinais à fitoterapia. São Paulo: Fapesp, 2002.

BARNES, J. et al. Different standards for reporting ADRS to herbal remedies and conventional OTC medicines: face-to-face interviews with 515 users herbal remedies. Journal of Clinical Pharmacology, Stamford, v. 45, n. 5, p. 496-500, 1998.

BERNARD, H. R. Research methods in cultural anthropology. London: Sage, 1988.

BRASIL. Agência Nacional de Vigilância Sanitária. Resolução. RDC nº 10, de 9 de março de 2010.

Diário oficial da União. Seção 1. p. 52-59.
BRASIL. Agência Nacional de Vigilância Sanitária. Resolução RDC n 48 , de 16 de março de 2004. Dispõe sobre o registro de medicamentos fitoterápicos. Diário Oficial da União, Brasília, DF, 18 mar. 2004. Disponível em: < http://

e-legis.anvisa.gov.br/leisref/public/showAct. php?id=10230 >. Acesso em: 15 fev. 2009.

BRUHN, J. G.; HOLMSTEDT, B.

Ethnopharmacology, objectives, principles and perspectives. In: BEAL, J. L.; REINHARD, E. (Ed.). Natural products as medicinal agents. Stuttgart: Hippocrates Verlag, 1981. p. 405-430.

CALDAS, E. D.; MACHADO, L. L. Cadmium, mercury and lead in medicinal herbs in Brazil. Food and Chemical Toxicology, New York, v. 42, n. 4, p. 599-603, 2004.

CALIXTO, J. B. Efficacy, safety, quality control, marketing and regulatory guidelines for herbal medicines (phytoterapeutic agents). Brazilian Journal of Medical and Biological Research, São Paulo, v. 33, n. 2, p. 179-189, 2000.

CAMARGO, M. T. L. A. Plantas medicinais e de rituais afro-brasileiros II: estudo etnofarmacobotânico. São Paulo: Ícone, 1998.

CARLINI, E. A.; GALDURÓZ, J. C. (Org.). II Levantamento domiciliar sobre o uso de drogas psicoativas no Brasil: estudo envolvendo as 108 maiores cidades do país. São Paulo: SENAD, 2006.

DELAY, J.; DENIKER, P.; LEMPERIERE, T. New contributions in psychopharmacology. Paris: Acquisitions Medicales Recentes, 1959.

ELVIN-LEWIS, M. Should we be concerned about herbal remedies. Journal of Ethnopharmacology, Lausanne v. 75, n. 2/3, p. 141-164, 2001.

FARIAS, M. R. et al. O problema da qualidade dos fitoterápicos. Caderno de Farmácia, Porto Alegre, v. 1, n. 2, p. 73-82, 1985.

FOOTE-WHYTE, W. Treinando a observação participante. In: GUIMARÃES, A. Z. (Org.). Desvendando máscaras sociais. 2. ed. Rio de Janeiro: Francisco Alves, 199o. p. 77-86.

FREITAS, V. M. et al. Freqüência de uso de inibidores de fosfodiesterase-5 por estudantes universitários. Revista de Saúde Pública, São Paulo, v. 42, n. 5, p. 965-967, 2008. 
HEINRICH, M. et al. Fundamental of pharmacognosy and phytotherapy. Edinbrugh: Churchill Livingstone, 2004.

IPEA - INSTITUTO DE PESQUISA ECONÔMICA APLICADA; PNUD - PROGRAMA DAS NAÇÕES UNIDAS PARA O DESENVOLVIMENTO. Relatório sobre o desenvolvimento humano no Brasil 2000. Brasília, DF: PNUD; Rio de Janeiro: IPEA, 2000.

MALINOWSKI, B. Objeto, método e alcance desta pesquisa. In: GUIMARÃES, A. Z. (Org.). Desvendando máscaras sociais. 2. ed. Rio de Janeiro: Francisco Alves, 199o. p. 39-61.

MARTIN, G. J. Ethnobotany: a methods manual. London: Chapman and Hall, 1995.

MOURA, M. R. L.; REYES, F. G. R. Interação fármaco-nutriente: uma revisão. Revista de Nutrição, Campinas, v. 15, n. 2, p. 223-238, 2002.

NIERO, R. L. et al. Aspectos químicos e biológicos de plantas medicinais e considerações sobre fitoterápicos. In: BRESOLIN, T. M. B.; CECHINEL FILHO, V. (Org.). Ciências farmacêuticas: contribuição ao desenvolvimento de novos fármacos e medicamentos. Itajaí: UNIVALI, 2003. p. $10-56$.

NIGGEMANN, B.; GRÜBER, C. Side-effects of complementary and alternative medicine. European Journal of Allergy and Clinical Immunology, Copenhagen, v. 58, n. 8, p. 707-716, 2003.

NORDENG, H.; HAVNEN, G. C. Impact of sociodemographic factors, knowledge and attitude on the use of herbal drugs in pregnancy. Acta Obstetricia et Gynecologica Scandinavica, Gothenburg, v. 33, n. 84, p. 26-33, 2005.

ORGANIZAÇÃO MUNDIAL DA SAÚDE. Declaração de Alma Ata: conferência internacional sobre cuidados primários de saúde. URSS - Alma Ata, 1978.

PINHO, R. S. N. de. Uso de estimulantes, queixas do sono e estado de humor em motoristas profissionais de caminhão. 2005. Dissertação (Mestrado em Ciências Farmacêuticas) - Faculdade de Ciências Farmacêuticas da Universidade Federal do Ceará, Fortaleza, 2005.
PIRES, J. M. et al. Antinociceptive peripheral effect of Achillea millefolium L. and Artemisia vulgaris L.: both plants known popularly by brand names of analgesic drugs. Phytotherapy Research, London, v. 23, n. 2, p. 212-219, 2009.

\section{PROGRAMA DAS NAÇÕES UNIDAS PARA O} DESENVOLVIMENTO. Atlas de Desenvolvimento Humano: municipal, Brasil, 1991 e 2000. Disponível em: <http://www.pnud.org.br/atlas/> Acesso em: 15 fev. 2009.

RIBEIRO, P. C. P. O uso indevido de substâncias: esteróides anabolizantes e energéticos.

Adolescencia Latinoamericana, Porto Alegre, v. 2, n. 2, p. 97-101, 2001.

RODRIGUES, E. Plants of restricted use indicated by three cultures in Brazil (cabocloriver dweller, indian and quilombola). Journal of Ethnopharmacology, Lausanne, v. 111, n. 2, p. 295302, 2007.

SPINELLA, M. The psychopharmacology of herbal medicine: plant drugs that alter mind, brain, and behavior. Cambridge: Massachusetts Institute of Technology, 2002.

TIRAN, D. The use of herbs by pregnant and childbearing women: a risk-benefit assessment. Complementary Therapies in Nursing \& Midwifery, New York, v. 9, n. 4, p. 176-181, 2003.

TUROLA, M. S. R.; NASCIMENTO, E. S. Informações toxicológicas de alguns fitoterápicos utilizados no Brasil. Revista Brasileira de Ciências Farmacêuticas, São Paulo, v. 42, n. 2, p. 289-306, 2006.

VEIGA JUNIOR, V. F.; PINTO, A. C. Plantas medicinais: cura segura? Química Nova, São Paulo, v. 28, n. 3, p. 519-528, 2005.

WORLD HEALTH ORGANIZATION. Investing in mental health. Geneva, 2003.

Recebido em: 15/05/2009

Reapresentado em: 06/03/2010

Aprovado em: 08/03/2010 